Article

\title{
Experimental Study on the Reliability of PBGA Electronic Packaging under Shock Loading
}

\author{
Jiang Shao ${ }^{1, *}$, Hongjian Zhang ${ }^{2}(\mathbb{D})$ and Bo Chen ${ }^{2}$ \\ 1 China Aero-Polytechnology Establishment, Beijing 100028, China \\ 2 China Jiangsu Province Key Laboratory of Aerospace Power System, Nanjing University of Aeronautics and \\ Astronautics, Nanjing 210016, China; zhanghongjian@nuaa.edu.cn (H.Z.); chenbo_best@163.com (B.C.) \\ * Correspondence: saviola80@sina.com; Tel.: +86-137-17879887
}

Received: 27 December 2018; Accepted: 23 February 2019; Published: 2 March 2019

\begin{abstract}
Plastic Ball Grid Array (PBGA) one of the most important electronic packaging methods, is widely used in aeronautical industry field. According to the JEDEC standard, shock tests of PBGA assemblies are conducted under different loading conditions. Several important parameters, such as the fatigue life of PBGA assemblies, the relationship between solder joint positions and fatigue life, the relationship between strain energy density and fatigue life, are analyzed based on experiment results. The failure modes of PBGA assemblies are studied by optical microscope (OM). The results show that during the shock tests, the strains of the solder joints near the center of the specimen are larger than other positions, and these solder joints are prone to form micro cracks. With the increase of the shock times, these micro cracks extend rapidly which will eventually cause the failure of the PBGA electronic packaging.
\end{abstract}

Keywords: PBGA; reliability; shock tests; failure life

\section{Introduction}

Ball Grid Array (BGA) Package technology is one of the most important and popular electronic packaging methods in the modern electrical and aeronautical industry field and it has many advantages such as good heat matching, low costs, good electrical properties, etc. [1]. During its usage period in the aircraft, mechanical shock loading is very common, the research on reliability under shock loading is very important for avionics electronic products.

Early attention to the reliability problem of microelectronics packaging under thermal and mechanical shock loading is designated to foreign communications companies such as Motorola, Lucent technologies. Wu and Song [2] studied the drop shock influence on communication products by means of experiment and simulation. Goyal and his colleagues of Lucent technologies studied the drop shock influence on thin-walled shell phone by a drop shock test and found that cell phone shell stiffness was insufficient under the action of shock loading, and components were prone to crack, and the shape and size of the mobile phone's effects on component failure were extremely significant [3]. In order to simulate the product process more realistically, Goyal and Buratynski $[4,5]$ proposed a new drop testing instrument. Ong Y C studied drop shock testing on the Nokia 3210 mobile phone in the product level and board level [6]. Tong Yan Tee and Jing-en Luan proposed Input-G model in the board-level drop simulation [7-10]. Desmond Y R compared the shock resistance of PBGA (plastic ball grid array), VQFN (very thin quad flat no-lead), and PQFP (plastic quad flat pack) packaging components, and the results showed that VQFN solder joints' shock resistance was the best [11]. In China, many scholars have also done a lot of board level drop test and simulation work on electronic packaging successively. Zhou Dejian and Pan Kailin carried on the theoretical analysis and dynamic simulation on reliability problems in the drop shock of Thin Fine-Pitch Ball 
Grid Array (TFBGA) encapsulation component [12,13]. Qi Bo and Wang Jiaji studied the drop shock test on BGA encapsulation component, and analyzed microstructure and composition of the failure solder by SEM/EDX BGA [14,15]. Zhu Zhenjun and Zhao Mei studied the dynamic responses of PBGA solder joints under the environment of earthquake [16]. Qin Fei and Bai Jie established three dimensional finite element models of BGA encapsulation component by finite element software ANSYS and did simulation analysis on the deformation of printed circuit board (PCB) and the stress of solder joints by the method of Input-G [17,18]. Liu Weisheng did finite element drop simulation analysis of electronic chassis on the PCB using ANSYS/LS-DYNA, and simulated the whole process of drop shock, analyzing the drop height and cushion effect on the dynamic response of the PCB board [19]. Zhang Jie and Yang Ping studied effects of PBGA components' structure factors such as parameters and material properties on the solder joint stress by a combination of analytical method and finite element analysis [20]. Yau, Y.H, Mattila, T.T and Zhang, B. studied the dynamic mechanism of electronic devices, board under the drop impact [21-23].

This paper uses the Input-G method to conduct shock test on PBGA packaging PCB in board level following the JEDEC (Joint Electron Device Engineering Councils) standard. The failure modes of solder joints were determined and the failure lives of the solder joints were obtained by monitoring the current voltage signal of solder joints after the shock test. The strain of each component was obtained by using dynamic data acquisition instrument monitoring dynamic strain of PCB, S-N curve and P-S-N curve of solder joints were established. The static failures of solder joint were observed through the optical microscope and the failure reason of solder joints was analyzed.

\section{Test Design}

\subsection{Test Sample Design}

The test sample of printed circuit board (PCB) consists of 12 PBGA packaging devices and the design is shown as Figure 1. The real figure is shown as Figure 2. The length, width and thickness of the PCB boards are $180 \mathrm{~mm}, 160 \mathrm{~mm}$, and $2 \mathrm{~mm}$ individually, and the length and width of the PBGA packaging devices are both $21 \mathrm{~mm}$. Each PBGA has 36 solder joints, and the diameter is $0.5 \mathrm{~mm}$. The process parameters are as shown in Table 1.

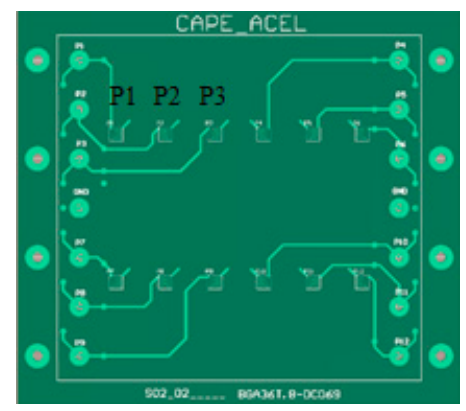

Figure 1. Printed circuit board (PCB) test sample.

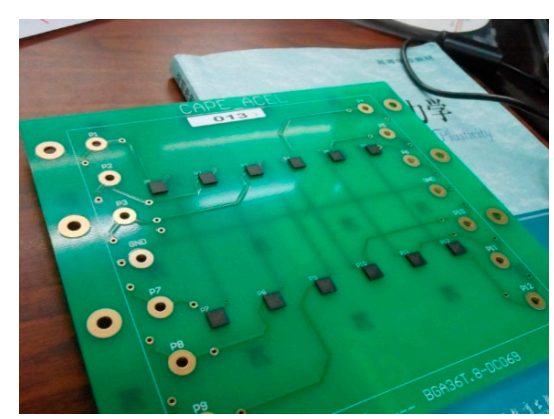

Figure 2. Real figure of test board. 
Table 1. PCB process parameters.

\begin{tabular}{ccccccc}
\hline $\begin{array}{c}\text { PCB } \\
\text { Material }\end{array}$ & $\begin{array}{c}\text { Layer } \\
\text { Number }\end{array}$ & $\begin{array}{c}\text { Welding Plate and } \\
\text { Wire Material }\end{array}$ & $\begin{array}{c}\text { Solder } \\
\text { Material }\end{array}$ & $\begin{array}{c}\text { Welding Plate } \\
\text { Processing }\end{array}$ & $\begin{array}{c}\text { Resistance } \\
\text { Welding }\end{array}$ & Handling Hole \\
\hline FR4 & 2 & $\mathrm{Cu}$ & Sn63Pb37 & $\begin{array}{c}\text { Chemical } \\
\text { zedoary }\end{array}$ & Double sides & $\begin{array}{c}\text { Resistance } \\
\text { welding }\end{array}$ \\
\hline
\end{tabular}

When installing the PCB during the test, it is important to ensure good welding of the signal line of the PCB and line hole of corresponding substrate to ensure good welding. Then, the transfer-base-table was fixed in the shock amplifier, the samples were fixed with hexagonal stainless steel bolt, and the sensor was tightened in amplifier to ensure firm without loose. Finally, signal and sensor lines were taped respectively on the table to prevent excessive force to cause damage or fracture in the process of shock, which is shown as Figure 3.

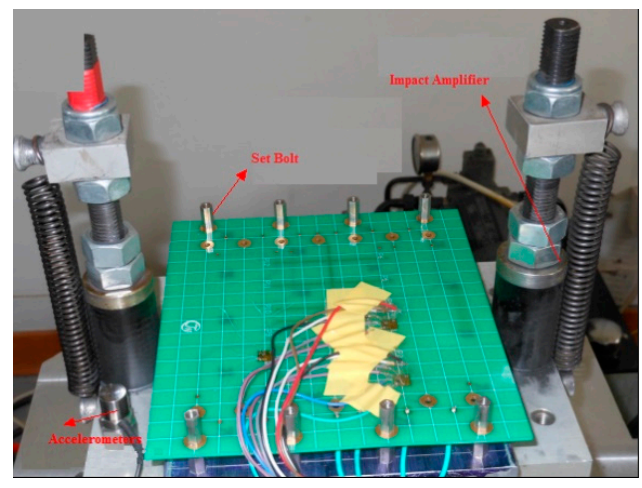

Figure 3. PCB fixation.

\subsection{Test Loading}

CL-20 impact test stand was used and the loading parameters are shown as Table 2.

Table 2. Environment parameters of shock test.

\begin{tabular}{ccccccccc}
\hline \multicolumn{3}{c}{ Height Parameters } & \multicolumn{3}{c}{ Cycle Parameters } & \multicolumn{3}{c}{ Brake Type and Delay Settings } \\
\hline $\begin{array}{c}\text { Test-bed's } \\
\text { total height } \\
(\mathrm{mm})\end{array}$ & $\begin{array}{c}\text { Increment } \\
\text { sensitivity } \\
(\mathrm{mm})\end{array}$ & $\begin{array}{c}\text { Benchmark } \\
\text { height } \\
(\mathrm{mm})\end{array}$ & $\begin{array}{c}\text { Cycle } \\
\text { numbers }\end{array}$ & $\begin{array}{c}\text { Time } \\
\text { interval } \\
(\mathrm{s})\end{array}$ & $\begin{array}{c}\text { Shock } \\
\text { waiting } \\
(\mathrm{s})\end{array}$ & $\begin{array}{c}\text { Trigger } \\
\text { brake } \\
(\mathrm{ms})\end{array}$ & $\begin{array}{c}\text { Dropping } \\
\text { brake } \\
\left(\mathrm{m} / \mathrm{s}^{2}\right)\end{array}$ & $\begin{array}{c}\text { Delay } \\
\text { time }(\mathrm{ms})\end{array}$ \\
\hline 1500 & 1 & 40 & Given & 0.5 & 0.5 & 5 & 9.8 & 10 \\
\hline
\end{tabular}

JEDEC standard JESD22-B111 'Board Level Drop Test Method of Components for Handheld Electronic Products' was used, and the typical shock test pulse of the standard is shown as Figure 4, and the formula is described as:

$$
A(t)=A_{0} \sin \left(\frac{\pi t}{t_{w}}\right)
$$

where $A_{0}$ is shock wave peak, and $t_{\mathrm{w}}$ is shock wave pulse width.

Test condition of JESD22-B110 is list as Table 3. Here test sample No. 013, 027, 035, and 036 use condition $\mathrm{B}$, namely peak acceleration is $1500 \mathrm{~g}$ and pulse duration is $0.5 \mathrm{~ms}$, test sample No. 026,028 , 030, and 033 use condition $\mathrm{G}$, the peak acceleration is $2000 \mathrm{~g}$ and pulse duration is $0.4 \mathrm{~ms}$, test sample No. 025 and 029 used condition $\mathrm{H}$, the peak acceleration is $2900 \mathrm{~g}$ and pulse duration is $0.3 \mathrm{~ms}$. 


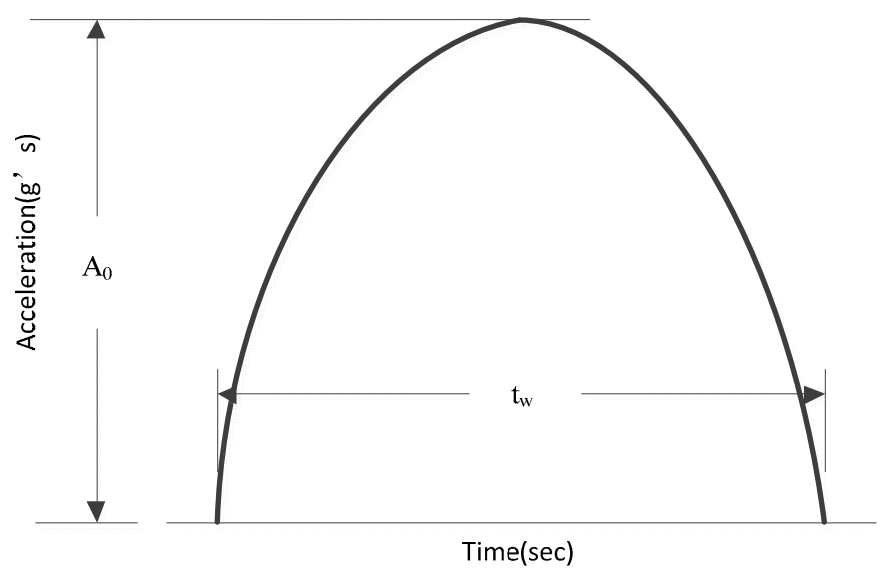

Figure 4. Shock pulse waveform, amplitude and pulse duration.

Table 3. Test Condition in JESD22-B110.

\begin{tabular}{ccc}
\hline Test Condition & Peak Acceleration $(\mathrm{g})$ & Pulse Duration $(\mathrm{ms})$ \\
\hline H & 2900 & 0.3 \\
G & 2000 & 0.4 \\
B & 1500 & 0.5 \\
F & 900 & 0.7 \\
A & 500 & 1.0 \\
E & 340 & 1.2 \\
D & 200 & 1.5 \\
C & 100 & 2.0 \\
\hline
\end{tabular}

The sampling frequency of high-speed dynamic data acquisition instrument for testing should be less than $50 \mathrm{KH}_{Z}$. If a daisy chain resistance is larger than $100 \Omega$ for the first time, the lasting time is larger than $1 \mu \mathrm{s}$, and the same phenomenon occurs larger than 2 times in the subsequent 5 times fall, the failure is defined as a transient failure in JEDEC standard. With the increase of falling number, the daisy chain resistance will increase, if larger than $1000 \Omega$, and it is defined as a static failure.

\section{Monitoring of Test Data}

In order to monitor the shock failure life of the solder joint, the real-time resistance of solder daisy chain needs to be monitored. Considering the difficulty of achieving the dynamic resistance monitoring, the real-time monitoring of solder joints can be achieved through a series of known resistance and monitoring voltage value of known resistance. Related transformation formula is shown as Equation (2).

$$
R_{0}=\frac{R_{x}(E-V)}{V}
$$

where, $R_{0}$ is a known resistance as $150 \Omega, R_{x}$ is daisy chain resistance, $E$ is the total voltage and $V$ is voltage of $R_{0}$. JEDEC standard shows that when the measured voltage is less than $3 \mathrm{~V}$ for 3 times in 5 times test, it is considered as a static failure. When the test voltage is less than $0.65 \mathrm{~V}$ and it is judged as a static failure. Voltage signal is acquired by Agilent U2531A high speed data acquisition system. The power output voltage value is set to $5 \mathrm{~V}$. Current of Path is $0.142 \mathrm{~A}$. Then real-time acquisition and data storage are done through the system software.

Strain detection was collected by DH5922 dynamic data acquisition instrument. Strain gages were sticked at the side of the PCB components without elements. During the process of dropping shock, the electrical measuring method was used to study the strain changes of PCB components, that was installed horizontally and its package was installed face down. Strain gage adopts BX120-2CA resistance strain gage with the resolution is $1 \% \mu \varepsilon$, and the length and width of the sensitive gate are $2 \mathrm{~mm}$ and $1 \mathrm{~mm}$, and the length and width of the base are both $7.2 \mathrm{~mm}$. The strain gage, which was 
sticked on the side of the PCB without components, was constructed testing bridge arm through strain modulator. Figure 5 is the shock test site.

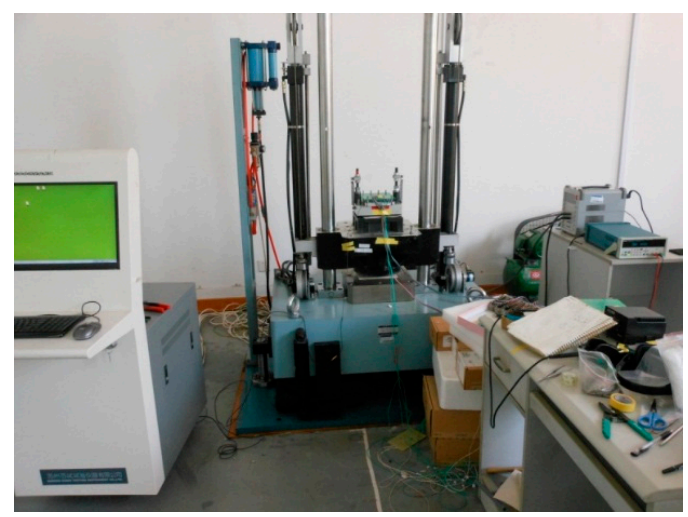

Figure 5. The shock test site.

\section{Test Data Analysis}

\subsection{Data Analysis}

The monitored devices in the test are P1, P2, and P3, which are shown in Figure 1. Partial data of the maximum values of strain, the number of first transient failures and the number of first static failures for one board in the drop shock test are shown in Table 4. The comparison of the results are analyzed as Figure 6.

Table 4. Test results.

\begin{tabular}{|c|c|c|c|c|c|c|}
\hline & & & $\begin{array}{c}\text { Strain } \\
\text { Maximum }(\mu)\end{array}$ & $\begin{array}{l}\text { Stress Maximum } \\
\quad(\mathrm{MPa})\end{array}$ & $\begin{array}{l}\text { Number of First } \\
\text { Transient Failures }\end{array}$ & $\begin{array}{l}\text { Number of First } \\
\text { Static Failures }\end{array}$ \\
\hline \multirow{13}{*}{$\begin{array}{l}1500 \mathrm{~g} / 0.5 \mathrm{~ms} \\
\text { (Condition B) }\end{array}$} & \multirow{3}{*}{ Board 013} & P1 & 741.9 & 5.564 & $>1,000$ & $>1,000$ \\
\hline & & P2 & - & - & 514 & 538 \\
\hline & & P3 & $2,057.4$ & 18.08 & 261 & 342 \\
\hline & \multirow{3}{*}{ Board 035} & P1 & 905.4 & 7.334 & $>1,000$ & $>1,000$ \\
\hline & & P2 & $1,172.4$ & 15.75 & 855 & 1027 \\
\hline & & P3 & $1,802.8$ & 17.16 & 593 & 603 \\
\hline & & P1 & 863.2 & 7.44 & $>1,000$ & $>1,000$ \\
\hline & \multirow{3}{*}{ Board 027} & P2 & 873 & 7.566 & 531 & 637 \\
\hline & & P3 & $1,980.7$ & 17.2 & 521 & 585 \\
\hline & & P1 & $1,857.8$ & 17.02 & $>1,000$ & $>1,000$ \\
\hline & \multirow{3}{*}{ Board 036} & P2 & $1,729.4$ & 13.88 & 949 & 1,148 \\
\hline & & P3 & $3,948.3$ & 29.13 & 104 & 116 \\
\hline & & P1 & $1,168.6$ & 20.82 & 65 & 69 \\
\hline \multirow{5}{*}{$\begin{array}{l}2900 \mathrm{~g} / 0.3 \mathrm{~ms} \\
\text { (Condition H) }\end{array}$} & \multirow[t]{3}{*}{ Board 029} & P2 & $1,241.8$ & 31.56 & - & 52 \\
\hline & & P3 & $1,845.6$ & 32.69 & - & 50 \\
\hline & & P1 & $1,494.9$ & 13.10 & 82 & 87 \\
\hline & \multirow{3}{*}{ Board 025} & P2 & $1,829.6$ & 21.70 & - & 27 \\
\hline & & P3 & $2,523.2$ & 29.91 & - & 26 \\
\hline \multirow{12}{*}{$\begin{array}{l}2000 \mathrm{~g} / 0.4 \mathrm{~ms} \\
\text { (Condition G) }\end{array}$} & & P1 & $1,610.1$ & 13.80 & 223 & 236 \\
\hline & \multirow{3}{*}{ Board 026} & P2 & $1,513.3$ & 16.74 & 78 & 90 \\
\hline & & P3 & $2,149.2$ & 25.01 & - & 47 \\
\hline & & P1 & $1,693.8$ & 14.50 & 109 & 135 \\
\hline & \multirow{3}{*}{ Board 028} & P2 & $1,635.8$ & 15.66 & - & 73 \\
\hline & & P3 & $2,360.7$ & 26.74 & - & 39 \\
\hline & & P1 & $1,850.8$ & 16.02 & - & 19 \\
\hline & \multirow[t]{3}{*}{ Board 030} & P2 & $1,550.3$ & 19.76 & - & 18 \\
\hline & & P3 & $2,306.4$ & 24.41 & - & 17 \\
\hline & & P1 & $3,071.4$ & 17.35 & 133 & 148 \\
\hline & \multirow[t]{2}{*}{ Board 033} & P2 & $2,203.7$ & 14.03 & - & 142 \\
\hline & & P3 & $2,806.3$ & 26.29 & - & 67 \\
\hline
\end{tabular}




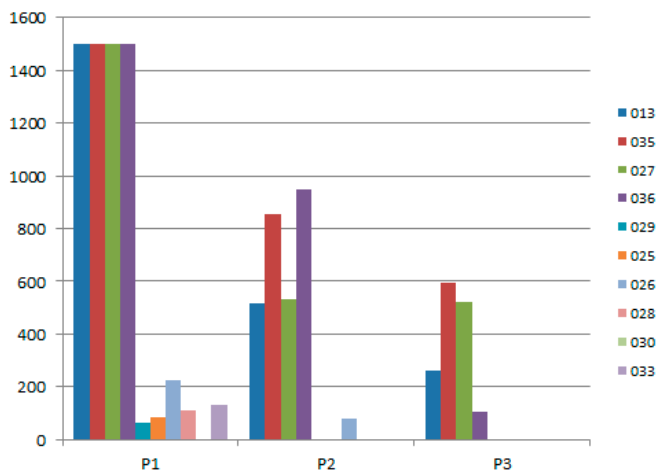

(a)

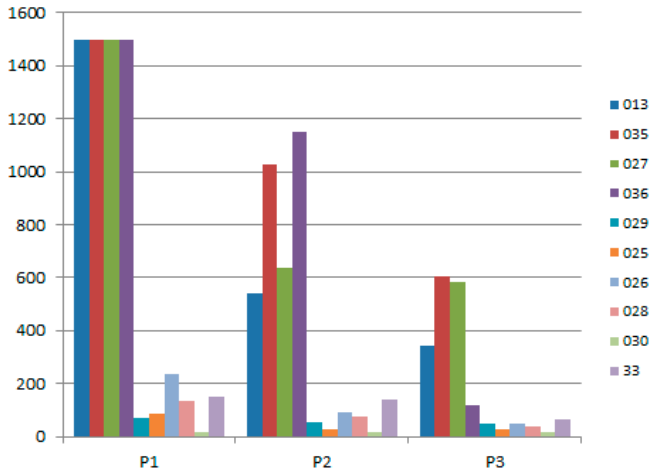

(b)

Figure 6. (a) Comparison of the number of first transient failure times at different points, (b) Comparison of the number of static failure times at different points.

With the increase of shock loading, the stress and strain of PCB board increases, and the life of solder joint is obviously reduced. At higher stress levels, the life of the solder joints at points P2 and P3 are similar and it is difficult to capture the transient failure of the solder joints. At the same strain of the test board, the number of the first transient failure and static failure decrease gradually with the strain increasing. And because the positions of P1, P2, and P3 are gradually near to the center, the strain gradually increases. Under the low shock, the reliability of P1 is larger than P2 and P3, because the position of $\mathrm{P} 2$ and $\mathrm{P} 3$ are more closed to the center, the test board can also produce large strain under the low shock. In order to ensure the product reliability, the P2 and P3 shock resistance need to be improved.

Figure 7 shows comparison of numbers of first time transient and static failures for the P1, $\mathrm{P} 2$, and P3, where the abscissa coordinate is the strain, the vertical coordinate is the failure times. The number of first transient failures and the number of first static failures decrease gradually with the increase of strain at the same point. When the transient failure occurs about 10 to 100 times, the static failure occurs. That is, when a certain amount of cracks occurs, the stress concentrations at the crack cause the crack propagation rate to be high, leading to the formation of large cracks, which leads to the failure of the solder joints.

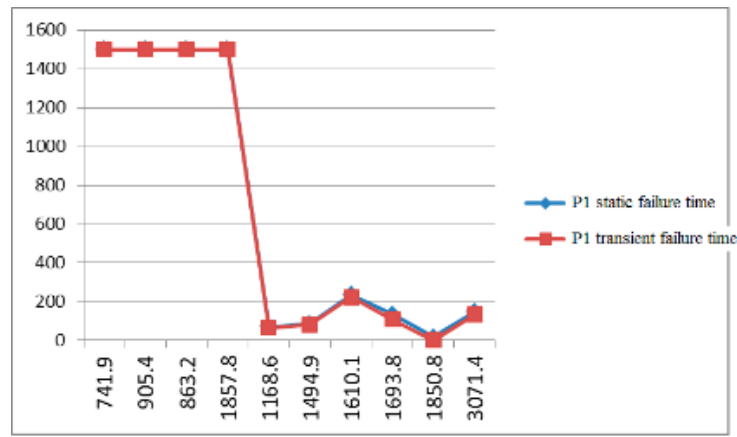

(a)

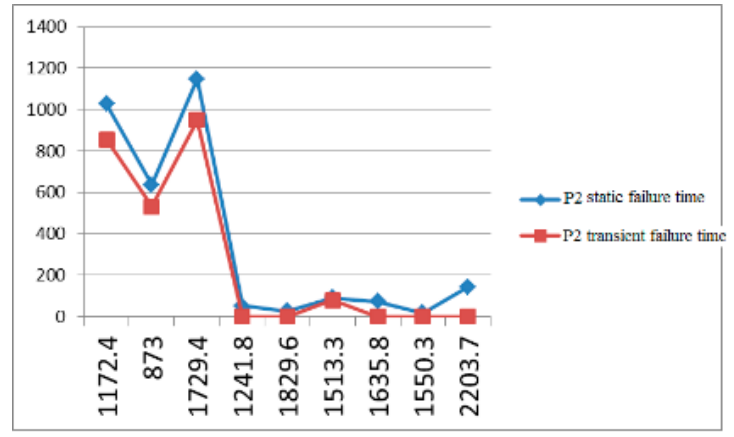

(b)

Figure 7. Cont. 


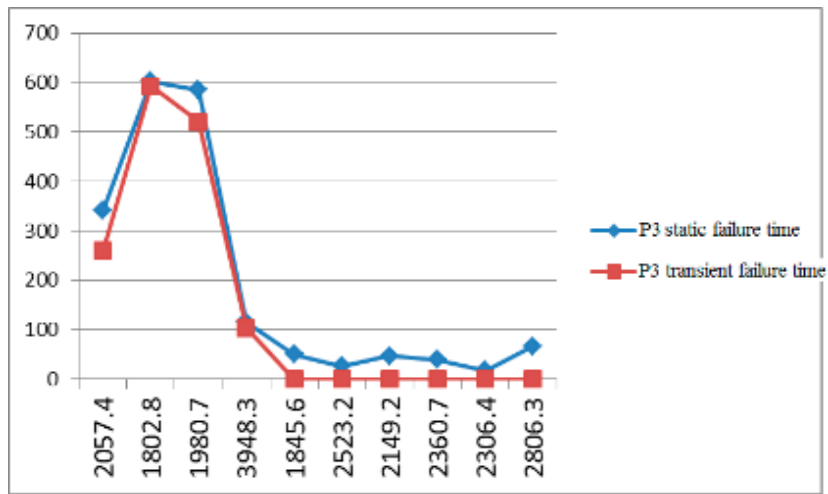

(c)

Figure 7. (a) P1 first transient, static failure comparison chart, (b) P2 first transient, static failure comparison chart, (c) P3 first transient, static failure comparison chart.

\subsection{Stress-Life Analysis}

The stress-life relationship of the test sample can be expressed by the following formula,

$$
a+b \lg \sigma_{\max }=\lg N
$$

where, $\mathrm{a}$ and $\mathrm{b}$ can be obtained by least squares fitting using Matlab software, the data $\sigma_{\max }$ and $N$ are in Table 4 , and the stress-transient failure life of the formula $a=1.7, b=-0.2173$. Then the stress-transient failure life curve is shown as Figure 8. In the stress-static failure life formula, parameters $a=1.526$, $b=-0.1381$ and the curve is shown as Figure 9.

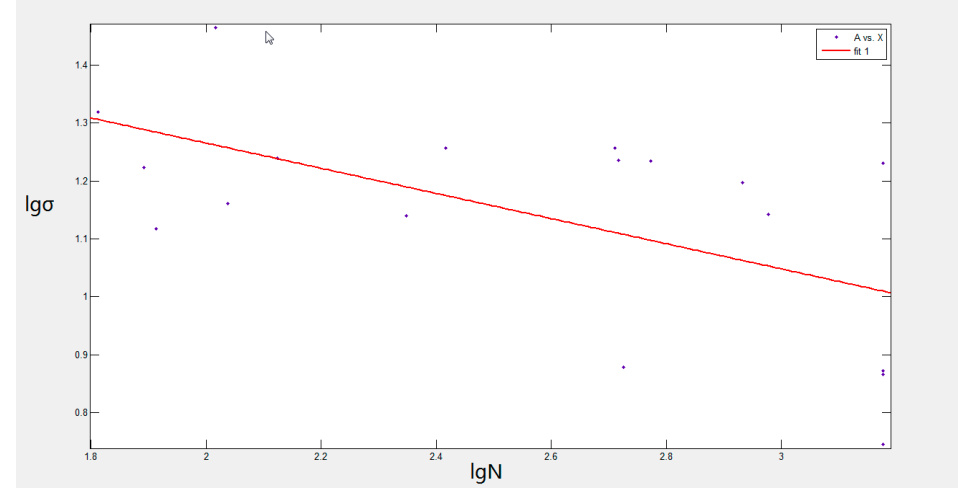

Figure 8. Failure life of the test sample.

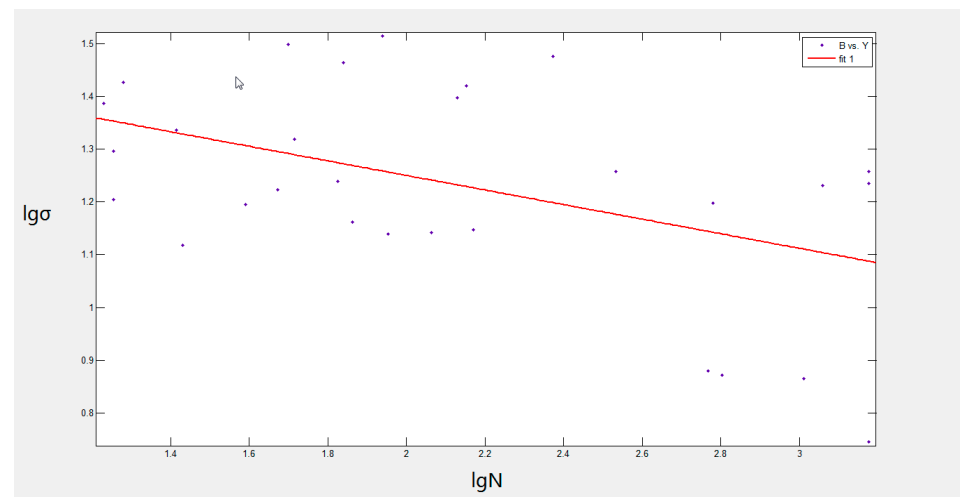

Figure 9. Stress-static failure life of the test sample. 
It can be seen from Figures 8 and 9 that the experimental data are close to the theoretical values at high stress levels, which is similar to the fatigue properties of general materials.

\subsection{Strain Energy Contrast Analysis}

Strain energy density can be expressed by the following formula,

$$
U=\frac{1}{2} \sigma \varepsilon
$$

where $\sigma$ is obtained from the following equation and here $E=1.11 \times 10^{10} \mathrm{~Pa}, \mu=0.28$.

$$
\sigma=\frac{\mathrm{E}}{2}\left[\frac{\varepsilon_{0}+\varepsilon_{90}}{1-\mu}+\frac{1}{1+\mu} \sqrt{\left(\varepsilon_{0}-\varepsilon_{90}\right)^{2}+\left(2 \varepsilon_{45}-\varepsilon_{0}-\varepsilon_{90}\right)^{2}}\right]
$$

The energy produced by all location point of all boards of the first static failure and transient failure is shown in Table 5.

\begin{tabular}{|c|c|c|c|c|}
\hline & & $\begin{array}{l}\text { Strain Energy Density } \\
\text { of a Single Drop }\left(\mathrm{J} / \mathrm{m}^{3}\right)\end{array}$ & $\begin{array}{l}\text { Strain Energy Density of the } \\
\text { First Transient Failure }\left(\mathrm{J} / \mathrm{m}^{3}\right)\end{array}$ & $\begin{array}{l}\text { Strain Energy Density of the } \\
\text { First Statistic Failure }\left(\mathrm{J} / \mathrm{m}^{3}\right)\end{array}$ \\
\hline & P1 & $2,063.97$ & $>2,063,970$ & $>2,063,970$ \\
\hline \multirow[t]{3}{*}{ Board 013} & P2 & - & - & - \\
\hline & P3 & $18,595.28$ & $4,853,368.08$ & $6,359,585.76$ \\
\hline & P1 & $3,320.10$ & $>3,320,100$ & $>3,320,100$ \\
\hline \multirow{3}{*}{ Board 035} & P2 & $9,232.65$ & $7,893,915.75$ & $9,481,931.55$ \\
\hline & P3 & $15,468.02$ & $9,172,538.23$ & $9,327,216.06$ \\
\hline & P1 & $3,211.10$ & $>3,211,100$ & $>3,211,100$ \\
\hline \multirow[t]{3}{*}{ Board 027} & P2 & $3,302.56$ & $1,753,658.83$ & $2,103,730.72$ \\
\hline & P3 & $17,034.02$ & $8,874,724.42$ & $9,964,901.7$ \\
\hline & P1 & $15,809.88$ & $>15,809,878$ & $>15,809,878$ \\
\hline \multirow[t]{3}{*}{ Board 036} & P2 & $12,002.04$ & $11,389,932.16$ & $13,778,341.92$ \\
\hline & P3 & $57,506.99$ & $5,980,726.91$ & $6,670,810.84$ \\
\hline & P1 & $12,165.13$ & $790,733.19$ & $839,393.97$ \\
\hline \multirow[t]{3}{*}{ Board 029} & P2 & $19,595.604$ & - & $1,018,971.41$ \\
\hline & P3 & $30,166.33$ & - & $1,508,316.6$ \\
\hline & P1 & $9,791.60$ & $802,910.79$ & $851,869.20$ \\
\hline \multirow{3}{*}{ Board 025} & P2 & $19,851.16$ & - & $535,981.32$ \\
\hline & P3 & $37,734.46$ & - & $981,095.86$ \\
\hline & P1 & $11,109.69$ & $2,477,460.87$ & $2,621,886.84$ \\
\hline \multirow[t]{3}{*}{ Board 026} & P2 & $12,666.32$ & $987,973.04$ & $1,139,968.80$ \\
\hline & P3 & $26,875.75$ & - & $1,263,160.06$ \\
\hline & P1 & $12,280.05$ & $1,338,525.45$ & $1,657,806.75$ \\
\hline \multirow[t]{3}{*}{ Board 028} & P2 & $12,808.31$ & - & $935,006.92$ \\
\hline & P3 & $31,562.56$ & $8,874,724.42$ & $1,230,939.80$ \\
\hline & P1 & $14,824.91$ & - & $281,673.25$ \\
\hline \multirow[t]{3}{*}{ Board 030} & P2 & $15,316.96$ & - & $275,705.35$ \\
\hline & P3 & $28,149.61$ & - & $478,543.40$ \\
\hline & P1 & $26,644.40$ & $3,543,704.54$ & $3,943,371.2$ \\
\hline \multirow[t]{2}{*}{ Board 033} & P2 & $15,458.96$ & - & $2,195,171.68$ \\
\hline & P3 & $36,888.81$ & - & $2,471,550.50$ \\
\hline
\end{tabular}

Table 5. The energy generated by the first transient, static failure and a single drop.

The strain energy density of each solder joints during static failure is shown as Figure 10. The total strain energy density of $\mathrm{P} 1, \mathrm{P} 2$, and $\mathrm{P} 3$ in high stress region is relatively stable. $\mathrm{P} 2$ and $\mathrm{P} 3$ are influenced by solder reflow process, so the dispersion in low stress region is larger, and the result is more concussion. But the sum of the strain energy of the PCB in the high stress region is relatively conserved. 


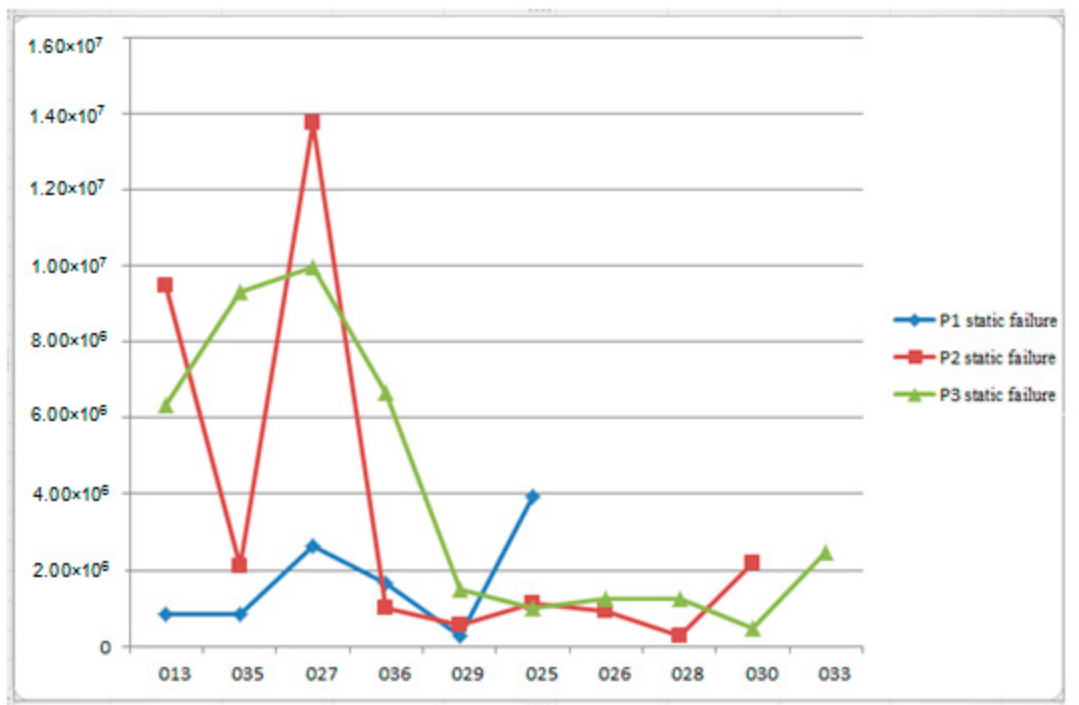

Figure 10. Strain energy density of each plate in static failure.

The strain energy density formula can be approximated as:

$$
U=\frac{1}{2} \frac{\sigma^{2}}{E}
$$

Considering the influence of energy on the life, the stress-life formula and the above equation are combined and we obtain,

$$
\lg N=a^{\prime}+\frac{b^{\prime}}{2} \lg U+\frac{b^{\prime}}{2} \lg 2 E
$$

The data in Tables 5 and 6 are substituted into the above formula, and the parameters $a^{\prime}=5.234$ and $b^{\prime}=-0.4474$ in the formula of strain energy density-life can be obtained by fitting and the strain energy density-life curve is shown as Figure 11. It can be seen that the trend of strain energy density and stress on life is close.

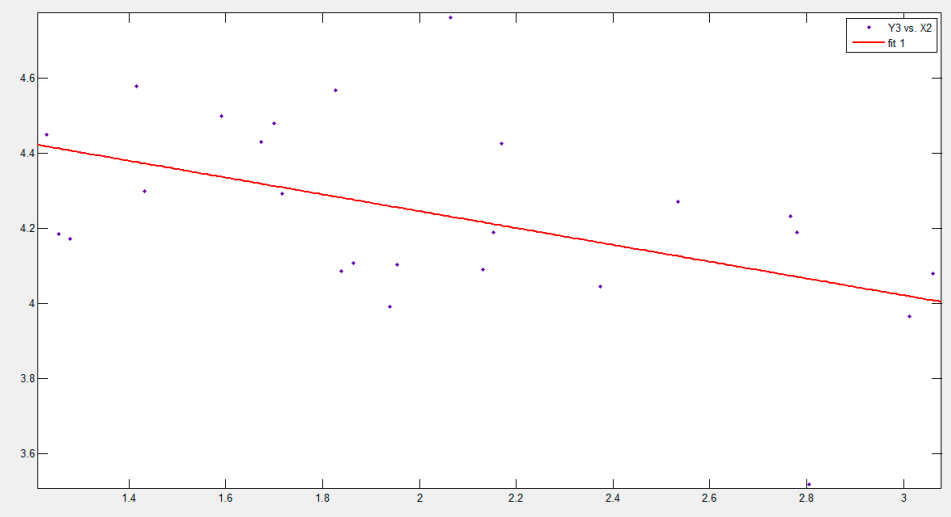

Figure 11. Strain energy density-life curve.

\subsection{Solder Joint Reliability Analysis}

Assuming that the reliability of solder joints obeys the Weibull distribution, and the distribution density function is:

$$
f(t)=\frac{m}{\eta}\left(\frac{t}{\eta}\right)^{m-1} e^{-\left(\frac{t}{\eta}\right)^{m}}
$$


By integrating $f(t)$, the failure distribution function $F(t)$ can be obtained:

$$
F(t)=1-e^{-\left(\frac{t}{\eta}\right)^{m}}
$$

The original equation can be converted to:

$$
\lg \lg [1-F(t)]^{-1}=m \lg t-m \lg \eta
$$

The left side of the equation is the failure rate and lgt is the lifetime. Consider board 013, 035, 027, 036 use B test condition, board 029,025 use $\mathrm{H}$ test condition, board 026, 028, 030, 033 use $\mathrm{G}$ test condition. Through the data fitting, the relationship between failure rate of the test board and lifetime under $\mathrm{B}$ and $\mathrm{H}$ test conditions is obtained, and it is shown in Figure 12.

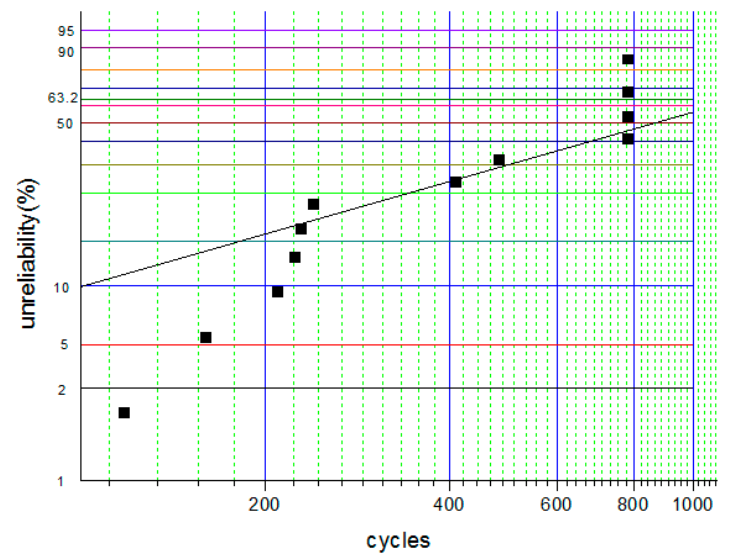

(a)

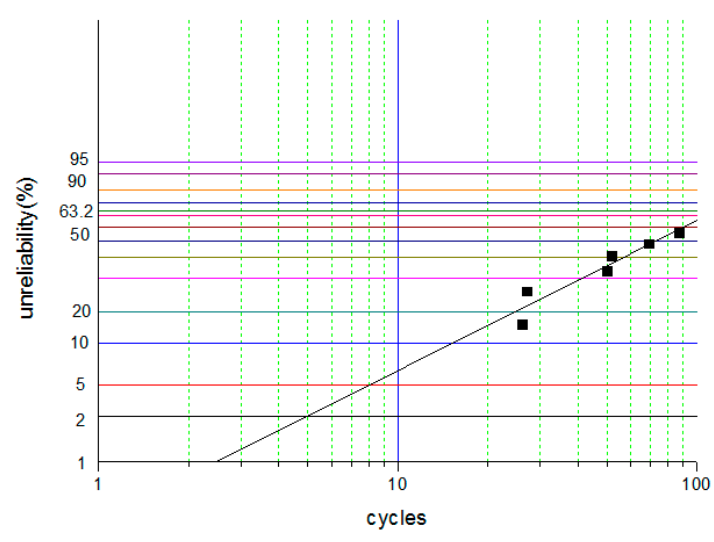

(b)

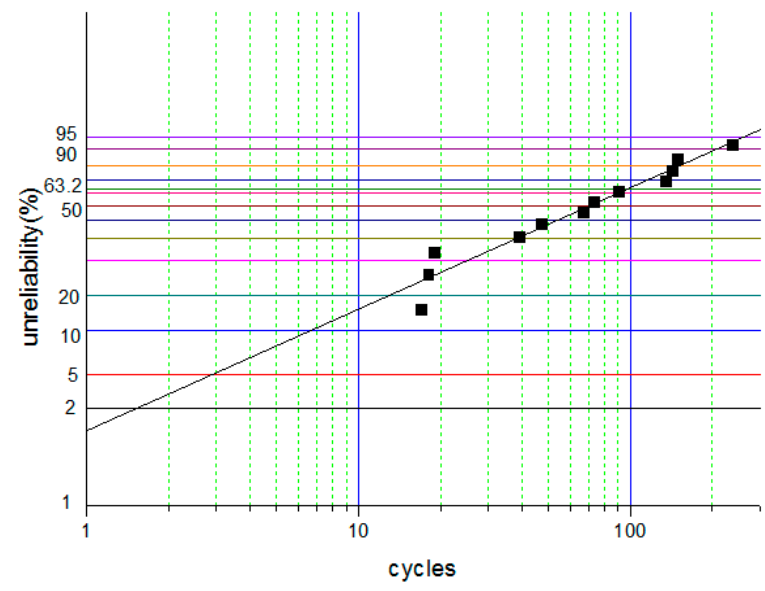

(c)

Figure 12. (a) Relationship chart of board failure rate and life under B test condition, (b) relationship chart of board failure rate and life under $\mathrm{H}$ test condition, (c) relationship chart of board failure rate and life under $\mathrm{G}$ test condition.

When the failure rate is $63.2 \%$, the life is the characteristic life, then transient and static characteristics life of the test conditions are shown as Table 6.

Table 6. Characteristics life under the B, H, and G test conditions.

\begin{tabular}{ccc}
\hline B Test Conditions & H Test Conditions & G Test Conditions \\
\hline 1239 & 74 & 102 \\
\hline
\end{tabular}




\subsection{P-S-N Curve}

Considering the experiment belonging to the small samples, the reliability of its confidence of the Probabilistic Stress-Life (P-S-N) curve need to be considered. Combined the relevant references, the fatigue life $\mathrm{N}_{\mathrm{P}, \mathrm{Y}}$ can be expressed as following:

$$
\lg N_{P, Y}=\overline{\lg N}\left(1-L_{P, Y} C_{V}\right)
$$

Which $\overline{\lg N}$ is the mean of logarithmic fatigue life; $L_{P, Y}$ is the single-margin factor and can be obtained through the look-up table; $C_{V}$ is the empirical statistics.

Considering the practical requirements, the confidence $\gamma$ is chosen to be $90 \%$. This paper presents safety probability in $90 \%, 95 \%$, and $99 \%$ of P-S-N curve. The selected number of samples ni is 29 , for welding components, $C_{V}$ is 0.035 , and single-sided statistical allowable coefficient table of the normal distribution shows that the values of $L_{P, Y}$ under $90 \%, 95 \%$, and $99 \%$ safe probability are: 1.655 , 2.089, and 2.896. Then transient failure PSN curve equation can be calculated by the equation 12 . Figure 13 shows the transient failure P-S-N curve. By the same methods, the static failure P-S-N curve and the strain energy-lifetime P-U-N curve are required as Figure 13.

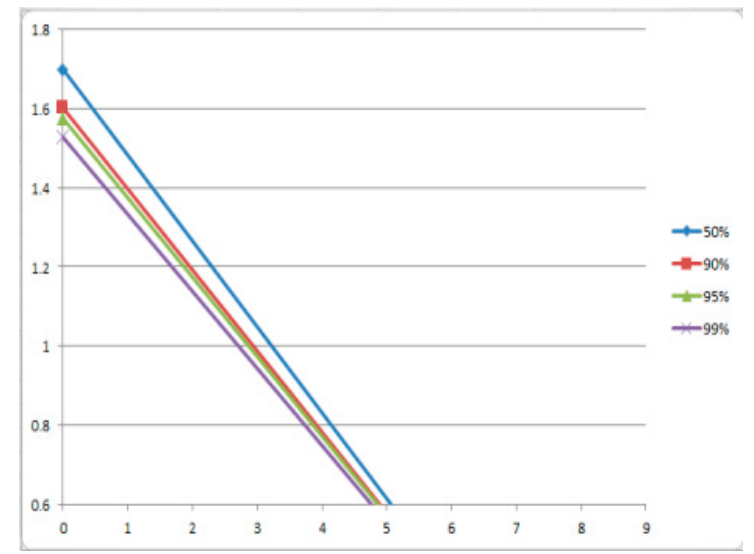

(a)

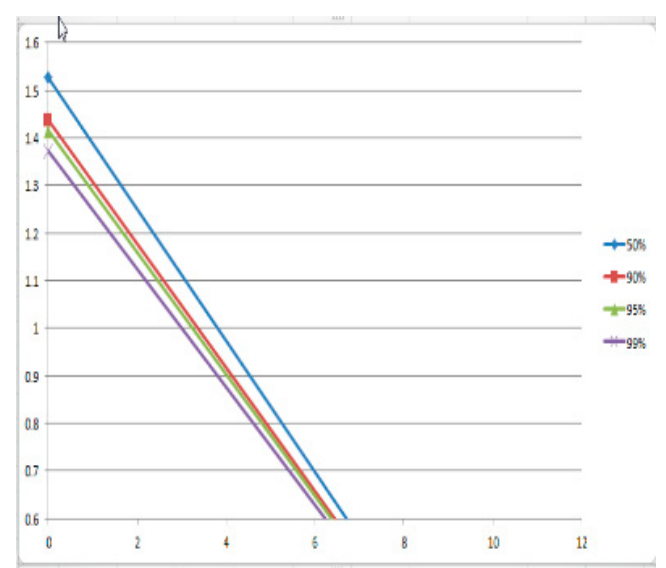

(b)

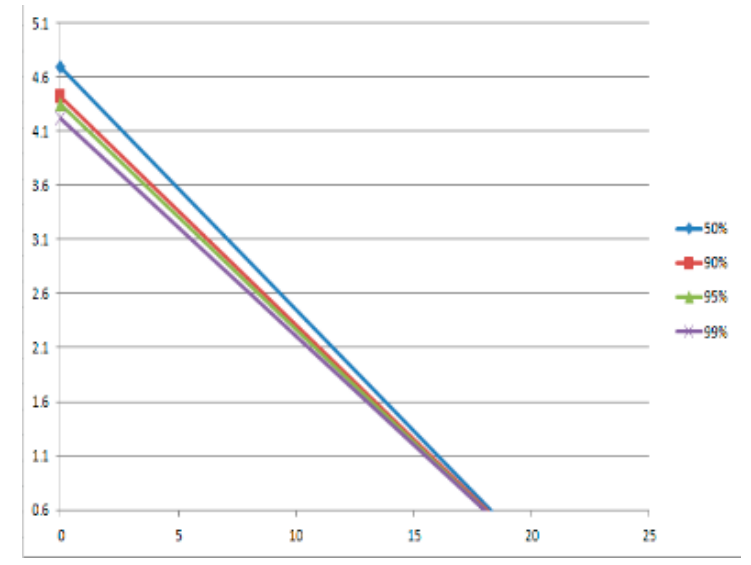

(c)

Figure 13. (a) Probabilistic Stress-Life (P-S-N) curve of transient failure, (b) P-S-N curve of static failure, (c) strain energy-lifetime (P-U-N) curve of strain energy-life.

From the above figures, the curves in the corresponding curve family are arranged in parallel, and the closer the curve is to the vertical axis, the higher the safety probability is. 


\subsection{Microscopic Analysis of Failure Solder Joints}

The main means of failure analysis include metallographic analysis, SEM and light microscopy. The study found that the common failure modes of the daisy-chain circuit were found to be the Intermetallic Compound (IMC) fracture on the one side of the PCB as shown in the Figure 14. The reason for this crack formation is that the surface damage is continuously diffused into the interior of the solder balls, causing local stress concentration to increase significantly and cause fracture. The figure shows a cross-sectional view of a sample of static failure solder joints under an optical microscope.

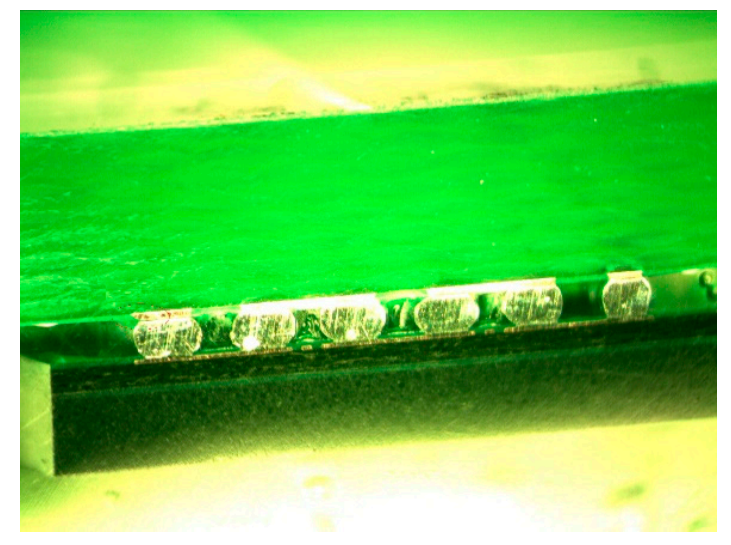

(a)

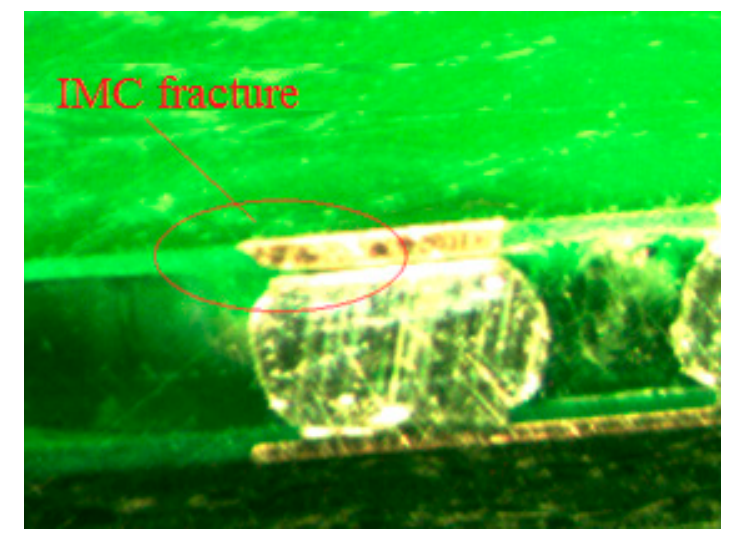

(b)

Figure 14. (a) A cross-sectional view of a sample of static failure solder joints taken under an optical microscope; (b) A fragmentary enlarged view of the fracture in the event of a static failure of the solder joint.

From the above two figures, the failure of the solder joints often occurs in the vicinity of the outside of the daisy chain solder bumps. In the mechanical shock of drop collision, PCB produces reciprocating bend, and in the PCB bending process, the solder balls are subjected to tensile stress, and more stress concentrated near the edges. In each drop process, the corner solder balls are subjected to tensile compressions, and the performances of stress are tensile stress, compressive stress and shear stress. Thus the corner ball is mostly prone to failure, and this is consistent with experiment results.

The material of solder joints in this experiment is $\mathrm{SnPb}$, and the hardness of $\mathrm{SnPb}$ is relatively low. Thus the cracks tend to appear inside the solder and further expand, and the entire fracture occurred in the interior of solder. Because the stress concentrates in the solder ball's hub and shroud, the failure crack is very close to the IMC layer.

\section{Conclusions}

(1) With the increase of shock loading, the stress and strain of PCB board increase, and the life of solder joint is obviously reduced. At higher stress levels, the life of the solder joints at points P2 and P3 are close to each other and it is difficult to capture the transient failure of the solder joints.

(2) At the same strain of the test board, the number of the first transient failure and static failure decrease gradually with the strain increasing. And because the position of P1, P2, and P3 increase gradually to the center, so the strain gradually increases. Under the low shock, the reliability of P1 is better.

(3) The number of first transient failures and the number of first static failures decrease gradually with the increase of strain at the same point. When the transient failure occurs about 100 times, the static failure occurs.

(4) The total strain energy density of P1, P2, and P3 in high stress region is relatively stable. P2 and $\mathrm{P} 3$ are influenced by solder reflow process, so the dispersion in low stress region is larger, and the 
result is more concussion. But the sum of the strain energy of the PCB in the high stress region is relatively conserved.

(5) The failure of the solder joints often occurs in the vicinity of the outside of the daisy chain solder bumps. Because the stress concentrates in the solder ball's hub and shroud, the failure crack is very close to IMC layer.

Author Contributions: Conceptualization and methodology, J.S.; test design, H.Z.; data acquisition and analysis, B.C. Funding: This research received no external funding.

Acknowledgments: I would like to thank Aviation Comprehensive Environment Laboratory (ACEL) of China Aero-Polytechnology Establishment (CAPE) for the test equipment and test site.

Conflicts of Interest: The authors declare no conflicts of interest.

\section{References}

1. Chinese Electronic Society Production Technology Books Editorial Board. Microelectronics Packaging Technology; China University of Science and Technology Press: Hefei, China, 2003; pp. 121-156.

2. Wu, J.; Song, G.S.; Yeh, C.-P.; Wyatt, K. Drop/Impact Simulation and Test Validation of Telecommunication Products. In Proceedings of the Therm'98. Sixth Intersociety Conference on Thermal and Thermomechanical Phenomena in Electronic Systems (Cat. No.98CH36208), Seattle, WA, USA, 27-30 May 1998; pp. 330-336.

3. Goyal, S.; Upasani, S.; Patel, D.M. Improving Impact Tolerance of Portable Electronic Products: Case Study of Cellular Phones. Exp. Mech. 1999, 39, 43-52. [CrossRef]

4. Goyal, S.; Buratynski, E.K. Methods for Realistic Drop-Testing. Int. J. Microcircuits Electron. Packag. 2000, $23,45-52$.

5. Buratynski, E.K.; Goyal, S.; Eugene, J.R. Realistic, Repeatable and Controllable Drop Testing. U.S. Patent US6374661B1, 23 April 2002.

6. Ong, Y.C.; Shim, V.P.W.; Chai, T.C.; Lim, C.T. Comparison of Mechanical Response of PCB Subjected to Product-Level and Board-Level Drop Impact Tests. In Proceedings of the 5th Electronics Packaging Technology Conference (EPTC 2003), Singapore, 12-12 December 2003; pp. 223-227.

7. Luan, J.E.; Tee, T.Y. Novel Board Level Drop Test Simulation using Implicit Transient Analysis with Input-G Method. In Proceedings of the 6th Electronics Packaging Technology Conference (EPTC 2004) (IEEE Cat. No.04EX971), Singapore, 8-10 December 2004; pp. 671-677.

8. Tee, T.Y.; Luan, J.E.; Pek, E.; Lim, C.T.; Zhong, Z. Novel Numerical and Experimental Analysis of Dynamic Responses under Board Level Drop Test. In Proceedings of the 5th International Conference on Thermal and Mechanical Simulation and Experiments in Microelectronics and Microsystems, Brussels, Belgium, 10-12 May 2004; pp. 133-140.

9. Luan, J.E.; Tee, T.Y.; Pek, E.; Lim, C.T.; Zhong, Z.; Zhou, J. Advanced Numerical and Experimental Techniques for Analysis of Dynamic Responses and Solder Joint Reliability During Drop Impact. IEEE Trans. Compon. Packag. Technol. 2006, 29, 449-456. [CrossRef]

10. Luan, J.E.; Tee, T.Y. Analysis of PCB Subassembly Dynamic Responses using Integrated Analytical, Numerical and Experimental Techniques. In Proceedings of the 6th International Conference on Electronic Packaging Technology, Shenzhen, China, 30 August-2 September 2005.

11. Chong, D.Y.R.; Che, F.X.; Pang, J.H.L.; Ng, K.; Tan, J.Y.N.; Low, P.T.H. Drop Impact Reliability testing for Lead-free and Lead-based Soldered IC Packages. Microelectron. Reliab. 2006, 46, 1160-1171. [CrossRef]

12. Pan, K.; Zhou, B.; Yan, Y. Drop Dynamic Responses and Modal Analysis for Board Level TFBGA. In Proceedings of the 2007 International Symposium on High Density packaging and Microsystem Integration, Shanghai, China, 26-28 June 2007.

13. Zhou, B. Unleaded portable electronics board level components of TFBGA drop reliability research. Master's Thesis, Guilin University of Electronic Science and Technology, Guilin, China, June 2007.

14. Qi, B. Ball grid array BGA seal fabrication of mechanical reliability analysis and prediction. Master's Thesis, Fudan University, Shanghai, China, June 2007.

15. Fan, Y.P.; Qi, B.; Wang, J.J. BGA solder ball under the board level drop test of fatigue crack behavior research. Semicond. Technol. 2008, 7, 585-588. 
16. Zhu, Z.J.; Zhao, M.; Guo, Q. PBGA solder joint under the environment of earthquake dynamic response finite element analysis. Vib. Shock. 2006, 25, 73-75.

17. Qin, F.; Bai, J.; An, T. Board level electronic packaging drop/impact of solder joint stress analysis. J. Beijing Univ. Technol. 2007, 33, 1038-1043.

18. Bai, J. In the process of the drop/impact the dynamics response of electronic packaging soldering contact. Master's Thesis, Beijing University of Technology, Beijing, China, June 2007.

19. Lu, W.S.; Feng, Z.H.; Zou, J.J. PCB based on ANSYS/1s-dyna drop simulation. J. Suzhou Univ. (Eng.) 2006, 26, 42-46.

20. Zhang, J. BGA solder joints under impact loading should be finite element simulation. J. Sens. Technol. 2006, 12, 1591-1598.

21. Yau, Y.H.; Hua, S.N. A comprehensive review of drop impact modeling on portable electronic devices. Appl. Mech. Rev. 2011, 64, 020803. [CrossRef]

22. Zhang, B.; Xi, J.S.; Liu, P.K.; Ding, H. Failure analysis of board-level Sn-Ag-Cu solder interconnections under JEDEC standard drop test. J. Electron. Mater. 2013, 42, 2848-2855. [CrossRef]

23. Mattila, T.T.; Ruotoistenmaki, H.; Raami, J.; Hokka, J.; Mäkelä, M.; Hussa, E.; Sillanpää, M.; Halkola, M. An approach to adjust the board-level drop test conditions to improve the correlation with product-level drop impact. Microelectron. Reliab. 2014, 54, 785-795. [CrossRef]

(C) 2019 by the authors. Licensee MDPI, Basel, Switzerland. This article is an open access article distributed under the terms and conditions of the Creative Commons Attribution (CC BY) license (http:/ / creativecommons.org/licenses/by/4.0/). 